\title{
MULHERES EM SITUAÇÃO DE VIOLÊNCIA CONJUGAL: FATORES RELACIONADOS À PERMANÊNCIA, ROMPIMENTO E RETORNO À RELAÇÃO VIOLENTA
}

Nara Maria Batista Cardoso*

SINTESE - 0 presente artigo apresenta alguns fatores relacionados à permanência, rompimento e retorno de mulheres agredidas à relação conjugal, bem como alguns depoimentos. Conclui-se que a conscientização das mulheres do seu papel na perpetuação desse ciclo é fundamental para que ela possa tomar-se a protagonista das mudanças na relação.

Palavras chaves: mulheres agredidas, permanência, rompimento
ABSTRACT - This paper presents some factors related to the permanence, separation and return of the battered wives to the marital relation and presents some testimonios. The conclusion is that women's consciouness about their roles in perpetuating this cycle is important to them to become the protagonist of these changes in relation.

Key words: battered wives, permanence, separation

\section{Introdução}

Permanecer na relação após sucessivos episódios de violência ou retornar a ela após períodos de separação tem sido uma constante na vida de mulheres que sofrem violência conjugal. Mulheres agredidas, em geral, apresentam um padrão de relação que se caracteriza, segundo Dobash e Dobash (1979), por três movimentos: permanecer na relação, separar-se e voltar a conviver com o marido. $O$ presente artigo apresenta alguns fatores relacionados a esse padrão, bem como alguns depoimentos de mulheres agredidas. $O$ processo de conscientização da mulher do seu papel na perpetuação desse ciclo é fundamental para que ela possa tornar-se a protagonista das mudanças na relação.

- Universidade de Santa Cruz do Sul, UNISC.

\begin{tabular}{|l|l|l|l|l|l|}
\hline VERITAS & Porto Alegre & v. 42 & $\mathrm{n}^{2} 1$ & Março 1997 & p. 133-139 \\
\hline
\end{tabular}




\section{Fatores relacionados à permanência na violência}

Em um trabalho de pesquisa recente (Cardoso, 1996) através de entrevistas de depoimento com dezesseis mulheres agredidas e através de análise de conteúdo pode-se constatar alguns fatores relacionados à permanência na situação de violência.

Um fator importante eram as freqüentes alterações no comportamento do marido, ora violento, ora calmo, que traziam esperanças em oito das mulheres entrevistadas de que ele poderia, efetivamente, modificar a sua conduta, deixando de agir com violência. Por exemplo, as promessas do marido de que não mais abusaria do álcool fazia com que elas retornassem para a convivência, sentindo-se motivadas a recomeçar uma vez mais o relacionamento, tendo em vista a expectativa de alterar a situação.

C. R. levou algum tempo para entender as mudanças no comportamento dele e relatou que se fosse sempre violento ela teria rompido a relação há mais tempo. Ele tentava deixar de usar drogas, mas tinha uma recaída e começava tudo de novo. Ela pensou durante muito tempo que poderia mudar a situação, mas reconhece que: "era sempre como um círculo, sempre as mesmas coisas, não muda muito, um pouquinho, depois começa de novo..."

$\mathrm{O}$ fato de o marido mudar de comportamento freqüentemente parece ser, também, um fator que estimulava A a permanecer na relação: "Otra hora ele dizia, parece que era uma coisa, bah, não, tu não vai saí de casa, com tudo que ele me mandava, não, nós vamo se dá bem, eu não vô brigá mais contigo, vai fazê treze ano que nós temo junto, vamo se dá, cria nossos filho, aquiá a poquinho ele já mudava, já tava ... É, dizia isso e mandava coragem de fica em casa e, por isso que tinha corage de fica em casa, otra mulher eu não arrumo igual a tu dizia prá mim."

R. também alegou que, com ele, em alguns momentos sentia-se amparada e protegida, o que lhe dificultou separar-se dele.

A necessidade de a mulher manter a relação ainda que para isso precise sacrificar-se e assumir a responsabilidade por tudo o que ocorre nesse relacionamento foi analisado por Walker (1979) e NiCarthy (1986). Isto foi associado à socialização feminina tradicional que inculca na mulher o mito de que para ser considerada um ser completo, necessita ter permanentemente um companheiro. Quando ela consegue enfrentar o medo e decide separar-se, seu marido inicia um jogo emocional, apelando para o seu perdão, prometendo modificar-se. Esta situação provoca na mulher o desejo de tentar, uma vez mais, mudar o comportamento do marido, partindo da idéia de que deve ser mais confiante e dedicada. Desta forma inicia-se e reinicia-se o ciclo da violência.

Associada a este padrão está, também, a falta de um lugar para ir com os filhos, fator que se mostrou importante para dez das mulheres entrevistadas.

Z. relatou que convivia com o marido porque não tinha um lugar para abrigarse e, além disso, tinha medo de sair de sua casa, pois não queria tornar-se uma prostituta. Além disso, não tinha vontade de separar-se da filha, pois temia que esta pudesse sofrer abuso sexual do pai da mesma forma que ela sofrera na sua infância. 
A existência de filhos aparece como uma justificativa para a permanência da mulher na relação. A. enfatizou a impossibilidade de conciliar o trabalho e o cuidado com os filhos. O fato de ter uma filha com o marido fez com que S. L. e Ma permanecessem na relação. Além disso, a filha de Ma era portadora de deficiência mental, o que agravava ainda mais as suas dificuldades para separar-se porque necessitava de recursos adicionais para cuidá-la e educá-la. As solicitações da filha de C. para que ela continuasse a viver com o pai e também não a privasse dessa convivência faziam-na repensar uma vez mais a decisão de afastar-se da relação.

Outro fator associado a este padrão é que além da falta de um lugar para permanecer com os filhos, três das depoentes não poderiam contar com a ajuda econômica da família para sair de sua casa. Retornavam para a relação porque não tinham possibilidades de manter-se por muito tempo com os filhos: além de um lugar específico para viver com eles, faltava-lhes recursos econômicos.

De acordo com Walker (1979), embora os filhos e filhas de mulheres agredidas possam sofrer conseqüências graves em nível físico, emocional e educacional, algumas mulheres justificam sua permanência na relação porque não querem privar os filhos da convivência com o pai. Na realidade, segundo a autora, esta é uma justificativa que não se sustenta porque os filhos adquirem autonomia e deixam a casa familiar. Isto reforça a idéia de que a união simbiótica e traumática do casal é um fator fundamental na manutenção da relação violenta e não somente a presença dos filhos. A autora está correta na sua análise, embora se faz uma ressalva de que não se deve menosprezar as condições de vida, o número de filhos e as carências que existem para sustentá-los e educá-los nas classes populares, conforme relataram as próprias mulheres desta pesquisa.

Quatro mulheres explicaram que sua tentativa de separar-se e romper com o ciclo da violência fazia com que o marido intensificasse as agressões, chegando até a tentativas de homicídio. O medo gerado pelas constantes ameaças a si própria e a membros da sua família aparece como um fator associado à permanência dessas mulheres.

S. I. explica que não tinha para aonde ir, um lugar seguro onde ele não a encontrasse e batesse nela; quando a encontrava ameaçava-a com uma faca e levava-a para a casa: "ele sempre tava de faca, se abrisse a boca ele ia me esfaqueá".

Entende que se esforçou para ficar com ele pela filha que é dele e que gosta muito do pai.

S. tinha muito medo que seu marido a matasse, pois já sabia que ele era perigoso e, além disso, ameaçava agredir a família dela. Ele era traficante e ameaçava a vida de um irmão dela que também era traficante, ele mesmo dizia: "eu sei que tu tá comigo porque tu tem medo, tu não tem coragem de sair.' Um dia eu disse pra ele: 'Um dia eu vou me embora, ninguém vai saber onde que eu tô, nem a minha família, nem ninguém.' Ele dizia assim: 'Duvido, tu não vai daqui nem até a casa da tua mãe o único lugar que tu sabe ir'."

Para Dutton e Painter (1981), nas relações com violência ocorre o que se denominou lavagem cerebral "união traumática" em que há um grave processo de intimidação psicológica da mulher dificultando-lhe buscar os recursos necessários 
para solucionar os problemas existentes. Da mesma forma, para Kidd e Chayet (1984), o medo, o desamparo e a ameaça de vitimização posterior são fatores inibidores importantes para que as vítimas não denunciem o ocorrido e não consigam romper a relação.

C. R. queixa-se do desemprego que lhe dificultaria manter-se economicamente a si e aos filhos. Isto foi também constatado nos estudos de Gelles (1987), Aguirre (1985), Strube e Barbour (1983 e 1984), Grossi (1994) que analisaram a reação de mulheres frente aos episódios de violência. Elas voltaram a conviver com o esposo por não terem recursos para manter-se e para planejar uma nova vida junto com seus filhos.

C. R. relatou ainda que os sentimentos de amor que nutria pelo marido faziam-na permanecer ao seu lado mas, ao mesmo tempo, reconhecia que continuava na convivência para punir-se de algo que não sabia identificar muito bem e que denominou "carma".

O sentimento de pena do marido fez com que duas mulheres permanecessem na relação.

Cl. permaneceu na convivência porque não desejava sair da sua casa, não permitindo que o marido tentasse apropriar-se dela. Além disso, estava envolvida em um processo judicial e o marido usava esta situação para ameaçá-la.

A aquisição e a preservação dos bens adquiridos, bem como a enfermidade terminal do marido faziam com que I. continuasse nesta convivência.

A proibição do marido de que convivesse com outras pessoas e buscasse trabalho fora de casa intensificava o isolamento de A. e impedia-a de buscar assistência para a violência sofrida.

De modo geral, alguns resultados do presente estudo são semelhantes aos identificados por Holtzworth-Munroe (1988), segundo os quais as explicações mais comuns das mulheres agredidas para permanecerem na situação de violência são: crença de que os maridos mudarão, dependência econômica, sentimento de pena e de amor por eles.

\section{Fatores relacionados ao rompimento com a violência}

Neste item são apresentados os fatores relacionados à separação descritos pelas mulheres entrevistadas em que se deu o rompimento da relação, mesmo que, posteriormente, houvesse um retorno para a mesma.

Duas das mulheres entrevistadas permaneciam na relação e não estavam tomando nenhuma providência para separar-se. Uma delas estava tentando separarse judicialmente e lutando para que o marido se afastasse da casa. O marido de outra estava preso há três meses por haver tentado abusar sexualmente de seus filhos.

As doze mulheres que se afastaram do marido encontravam-se aibergadas em uma instituição de apoio para mulheres agredidas. Estar lutando na justiça para a obtenção dos seus direitos configura a situação de todas essas mulheres.

A experiência de romper com a relação violenta estava sendo muito difícil para todas as mulheres entrevistadas. Exigia mobilização de recursos diversificados que, na maioria dos casos, não estavam disponíveis para elas. 
A falta de esperança de que o marido rompa com o ciclo da violência, a ausência de perspectivas de felicidade ao lado dele e de uma vida digna para ela e os filhos fez sete das mulheres entrevistadas não suportarem a violência e buscarem o apoio ou serem encaminhadas a uma instituição para albergá-las.

C. R., que no momento da entrevista se encontrava na instituição, reconhecia que estava decidida a mudar e que não teria um futuro feliz ao lado do marido: “... pode sê que até tu nem venha a tê, mas tu vai tê a chance de sonhá, né, de planejá, de fazê o futuro, mesmo que tu não consiga, tu vai lutá por aquilo, coisa que com ele eu não conseguia fazê, eu não podia trabalhá, eu queria estudá, não podia estudá, todo esse tipo de coisa, né, eu não podia nem sonhá... não era bem aquilo que eu queria, eu queria mais, e não queria vivê sempre sofrendo violência, vivê com aquele medo, aquela angústia, ele vai chegá assim ou não, será que ele vai chegá calmo ou não, uma sensação terrível tu ficá esperando naquela expectativa..."

Este fator chama a atenção para a importância de esclarecer-se às mulheres sobre o ciclo da violência conjugal.

A extensão da violência em relação aos filhos foi determinante na decisão de separar-se de seis mulheres entrevistadas. M. L., por sua vez, embora tenha se separado do seu marido em virtude de sua agressão aos filhos, não considerava uma justificativa suficiente. R. O. separou-se do marido porque ele tentou violentar sua filha e seu filho, embora reconhecesse que a situação já estava muito tensa antes deste episódio.

A ameaça do marido de colocar fogo na casa e o fato de tê-la expulsado de casa juntamente com os filhos, fez com que A. chegasse à instituição. Não desejava deixar sua casa, mas o marido obrigou-a a isto.

Embora ainda convivesse com o marido, C. queria separar-se porque não suportava o agravamento da violência em relação a ela e, ultimamente, em relação a sua filha. Além disso, não concordava com o fato de que o marido não mantinha economicamente a família. Também para $\mathrm{Cl}$., a exploração econômica por parte do marido, seus freqüentes e graves maus tratos (por exemplo, perda do olho e hematomas nos seios e no ventre) fizeram com que ela rompesse a relação violenta. $M$. A. rompeu a relação porque não suportava mais a violência que se agravava dia a dia e porque conseguiu um lugar para protegê-la das constantes agressões do marido.

M. explicou que se sentiu muito cansada de tanto sofrer violência. Na instituição sentia menos solidão e tinha possibilidades de conversar com outras mulheres sobre situações que foram vividas por todas. Segundo ela: “... queria que todas as mulheres tivessem coragem de saí, de fazer alguma coisa, porque ele nunca vai mudá, não adianta tu tentá, se tu saiu uma vez e voltô, aquela situação não muda mais, vai continuá a mesma coisa, tu saindo e voltando, tu apanhando, tu correndo risco de vida, tu enlouquecendo, eu já tava loca, eu escapei, porque um dia eu ia matá ele, só que graças a Deus, eu vi na hora que não ia adiantá nada, que eu ia deixá as criança rolando, porque se eles fazem, eles não são punidos, mas se a gente faz a gente é...." 
Quando não são resolvidos, a tendência dos incidentes de violência é agravaIem-se, bem como aumentarem a freqüência, com o passar do tempo.

Isto foi constatado por Walker (1984): $66 \%$ das mulheres disseram que a violência tornou-se mais freqüente, $65 \%$ que o abuso físico piorou e $73 \%$ que 0 abuso psicológico tornou-se mais severo.

Como se pode verificar pelos depoimentos obtidos nesta pesquisa e pelas análises de Ferraro e Johnson (1983), as explicações sobre a violência são influenciadas por fatores externos que se constituem em justificativas para que as mulheres não interrompam a relação. Quando as mulheres conseguem questionar tais justificativas, iniciam um processo de mudanças que as ajuda a entender a situação em que vivem de modo diferente. Este entendimento abrange as concepções da violência (compreendem que o marido não mudará); o nível e a visibilidade da violência (percebem o aumento da gravidade, da freqüência e da duração); o desespero frente à situação (sentem que a violência pode tornar-se fatal para elas e pode atingir os filhos); o relacionamento (não conseguem mais evitar a violência); os recursos econômicos (recebem algum tipo de apoio econômico e/ou social). É importante considerar os elementos que surgem a partir desses fatores como subsídios para a intervenção junto a mulheres agredidas.

Como se pode constatar a partir da análise dos depoimentos, o ciclo da violência é um fator relevante na permanência e no rompimento com a relação violenta. O processo de conscientização da mulher do seu papel na perpetuação do ciclo é fundamental para que ela possa tornar-se a protagonista das mudanças na relação e não se sinta responsável pela continuidade do relacionamento, o que implica em detrimento da sua saúde mental.

As mulheres tomam uma medida efetiva quando a violência se torna grave a ponto de comprometer a sua integridade física e/ou de seus filhos. Isto leva a pensar que poderá existir uma desconsideração com a sua própria vida $e$, conforme algumas mulheres relataram, um temor de que as suas filhas venham a sofrer abuso sexual como elas sofreram. Elas conseguem romper a relação em uma situação de emergência e desespero, com a sua auto-estima seriamente abalada.

\section{Referências bibliográficas}

AGUIRRE, B. E. "Why do they return? Abused wives in shelters." Social Work, [s.l], [s.v], [s.n.], p. 350354, July/August, 1985.

CARDOSO, N. M. B. (1996). Mulheres agredidas: reconstruindo histórias. Porto Alegre, 1996. Dissertação (Mestrado em Psicologia Social e da Personalidade), Faculdade de Psicologia,Pontifícia Universidade Católica do Rio Grande do Sul.

DOBASH, R. E; DOBASH, R. P. "Wives: the appropiate victims of marital violence". Victimology, [S.L.], v. 2, n. $3 / 4$, p. 426-42, 1977-1978.

DUTTON, D. G.; PAINTER, S. L. "Traumatic bonding: the development of emotional attachments in battered women and other relationships of intermittent abuse". Victimology: An International Joumal, [s.l], v. 6, n. 1-4, p. 139-155, 1981.

FERRARO, K. J; JOHNSON, J. M. "How women experience battering: the process of victimization". Social Problems, [s.1.], v. 30, n. 3, p. 325-339, 1983.

GELLES, R. J. "Power, Sex, and Violence: The Case of Marital Rape." In: Family Violence. California: Sage Publications, p. 135-149, 1987. 
GROSSI, P. K. Violência contra a mulher na esfera doméstica: rompendo o silêncio. Porto Alegre, 1994. Dissertação (Mestrado em Metodologia do Serviço Social) - Faculdade de Serviço Social. Pontifícia Universidade Católica do Rio Grande do Sul.

HOLTZWORTH-MUNROE, A. "Causal attribution in marital violence:theoretical and methodological issues". Clinical Psychogical Review, [s.l.], v. 8, [s.n.], p. 331-344, 1988.

XIDD, R. F; CHAYET, E. F. "Why do victims fail to report? The psychology of criminal victimization." Joumal of Social Issues, [s.1.], v. 40, n. 1, p. 39-50.

1984.

NICARTHY, G. Getting Free - You can end abuse and take back your life. Washington: The Seal Press, 1986.

STRUBE, M.A; BARBOUR, L. S. "The decision to leave an abusive relationship: economic dependence and psychological commitment." Joumal of Marnage and the Family, [s.l.], [s.v], [s.n.], p. 785-793, 1983.

STRUBE, M. A; BARBOUR, L. S. "The decision to leave an abusive relationship: economic dependence and psychological commitment. "Journal of Marriage and the Family", [s.l.], [s.v], [s.n.], 837844, 1984.

WALKER, L. The Battered Woman. New York: Harper and Row, 1979.

. The Battered Women Syndrome. New York; Springer Publishing Company, 1984. 